\title{
Effects of ankle instability type and bilateral leg on lower extremity kinetics during drop-landing
}

\author{
Kyoungkyu Jeon ${ }^{\mathrm{a}}$ \& Seunghyun Hyun ${ }^{\mathrm{b}}$ * \\ ${ }^{a}$ Assistant Professor, Dvision of Sport Science, Sport Science Institute, Health Promotion Center, College of \\ Arts and Physical Education, Incheon National University, Incheon, Korea \\ ${ }^{b}$ Research Professor, Department of Kinesiology, College of Natural Science, \\ Jeju National University, Jeju, Korea
}

\begin{abstract}
The purpose of this study was to investigate the analysis of the postural stability and leg stiffness according to the ankle instability types and bilateral legs during drop landing. Methods: Total 14 male athletes ( $n=7$ : mechanical ankle instability, $n=7$ : functional ankle instability) Participants in the experiment. The leg stiffness, leg length, peak vertical force, loading rate, as well as the DPSI (medial-lateral [ML], anterior-posterior $[\mathrm{AP}]$, vertical $[\mathrm{V}]$, dynamic postural stability index) during drop landing were calculated. To analyze the variables measured in this study, SPSS version 21.0 was used to calculate the mean and standard deviation, while a two-way ANOVA was used to evaluate the ankle instability types (MAI, FAI) with landing leg (left: dominant, right: non-dominant leg) results. Dimensionless leg stiffness and change of leg lengths showed increased with significantly in non-dominant leg and MAI type than in dominant leg and FAI type. This resulted from decrease in the leg lengths with leg stiff. MLSI showed increased with significantly in dominant leg than in non-dominant leg during drop landing. Mechanically unstable individuals demonstrated increased leg stiffness, which may increase risk of musculoskeletal. Also, mechanically unstable participants demonstrated greater loading rate variability, which may indicate difficulty mitigating landing forces with lax ligaments.
\end{abstract}

Key words: leg stiffness, ankle Instability, postural stability, dynamic postural stability index

\section{Introduction}

During running and closed kinetic chain exercises that involve contact with the ground during landing, the large impact force from the weight of the body must be absorbed by effectively moving the lower limb joints

Submitted : 18 March 2021

Revised : 9 June 2021

Accepted : 23 June 2021

Correspondence : hshyun0306@jejunu.ac.kr
(Blackburn \& Padua, 2008). Pressure is directly proportional to mass, and inversely proportional to contact area. Since individuals do not undergo significant changes in their body weight while performing sports activities, the impact force can be minimized by increasing the surface area over which an individual land.

However, many athletes tend to land on one foot rather than both feet to achieve their personal goals and 
move faster. As a result, they can experience a peak vertical force (PVF) up to 11 times their body weight when they use single leg support (McNitt-Gray, 1991). A large impact force produced upon landing momentarily exposes the body to a risk of injury, the most common of which are lateral ankle sprains (Brown, Padua, Marshall, \& Guskiewicz, 2009).

Lateral ankle sprains are often overlooked by athletes and their coaches. However, if not treated properly, they can recur, and lead to severe physical disabilities and loss of motor skills in $73 \%$ and $53 \%$, respectively, of people affected by them (Yeung, Chan, So, \& Yuan, 1994). Ankle instability (AI) can be classified as either mechanical ankle instability (MAI) or functional ankle instability (FAI). The former is defined as the physiologically relaxed state of the ankles due to repeated or severe sprains, and the latter is a subjective symptom that does not have a causal relationship with FAI (Brown et al., 2009; Hertel, 2002). These types of AI eventually progress to chronic ankle instability (CAI) (Hertel, 2002; Yeung et al., 1994).

However, studies that have compared motor functions between subjects with CAI and normal subjects using kinematic and kinetic parameters have reported inconsistent results (Brown et al., 2009; Caulfield, Crammond, O'Sullivan, Reynolds, \& Ward, 2004; Caulfield \& Garrett, 2002; Caulfield \& Garrett, 2004; Eamonn Delahunt, Monaghan, \& Caulfield, 2006; Delahunt, Monaghan, \& Caulfield, 2007; Gribble, Hertel, Denegar, \& Buckley, 2004). This may be because subjects who had partial MAI and FAI were both classified as having CAI (Brown et al., 2009).

Studies have investigated the characteristics of MAI and FAI based on the plantarflexion/dorsiflexion and inversion/eversion of the ankles, changes in the flexion/extension, and valgus/varus angles of the knees, and the components of ground reaction force during walking, stepping down, running, drop-jumping, and stop-jumping activities. However, according to dynamic systems theory, the sensory motor system arises from interactions between complex systems, such as the neuromuscular and musculoskeletal systems, the degrees of freedom in each system, and their limitations (James, 2004). During walking, running, and landing, numerous components of the musculoskeletal system, including muscles, tendons, and ligaments, work together to act like a spring. Leg stiffness can be controlled under various conditions if the lower limb can maintain normal functioning (Farley, Houdijk, Van Strien, \& Louie, 1998; Silder, Besier, \& Delp, 2015), and AI can affect this stiffness control.

Landing movements must be assessed under dynamic situations, and dynamic postural stability can be defined as the ability to maintain a balance while changing from a dynamic to a static state (Wikstrom, Tillman, Smith, \& Borsa, 2005). Static postural stability is also the result of the complex process of balance maintenance. In detail, the time required to achieve stabilization, which is an aspect of lower limb exercise control, is dependent on proprioceptive feedback, pre-programmed muscle patterns, and reflexive or voluntary muscle responses (Johnston 3rd, Howard, Cawley, \& Losse, 1998). In this context, it is more appropriate to assess the functional characteristics of MAI and FAI based on leg stiffness, which is determined more by the interactions between changes in leg length according to the lower limb flexion/extension angles as well as the impact force than by any single variable. In addition, ground reaction forces, which are produced during dynamic situations, such as landing, can be used to analyze precisely static postural stability. The high incidence of FAI and MAI resulting from sports activities suggests the need for new research on CAI and its prevention.

The present study sought to assess lower limb stiffness and postural stability for different types of AI. We aimed to investigate the characteristics and differences of athletes with FAI and MAI by measuring kinematic parameters, and provide quantitative data necessary for diagnosing and assessing patients during rehabilitation or treatment. 


\section{Methods}

\section{Participants}

Fourteen men (FAI: mean age: $21.28 \pm 1.11$ years, mean height: $1.77 \pm 0.11 \mathrm{~m}$, mean weight: $80.85 \pm 16.18$ kg, MAI: mean age: $21.41 \pm 1.90$ years, mean height: $1.75 \pm 0.35 \mathrm{~m}$, and mean weight $75.94 \pm 18.60 \mathrm{~kg}$ ) were enrolled in this study (Kruskal-Wallis test: age ( $p>.948)$, height ( $p>.060)$, weight $(p>.564)$. The participants had been diagnosed with FAI $(n=7)$ and MAI $(n=7)$ of the non-dominant ankle, and did not exhibit any problems with performing drop-landing tasks from a vertical height of $30 \mathrm{~cm}$. We defined FAI when scores ranged from 2 to 7 because this range of VAS scores correlated with significant functional instability estimated by the Cumberland Ankle Instability Tool (Hiller, Refshauge, Bundy, Herbert, \& Kilbreath, 2006; Wright et al., 2013). Individuals with VAS scores of $\geq 8$ were diagnosed as having MAI (Hiller, Kilbreath, \& Refshauge, 2011; Wright et al., 2013). This study was approved by the Institutional Review Board of Incheon University. Subjects provided written informed consent.

\section{Methodology}

For kinematic and kinetic measurement of the main joints of the lower limbs during drop-landing movements, a motion analysis device consisting of eight image analysis cameras (6 Eagle and 2 Raptor Camera System, Motion Analysis Corp., USA), and two force plates (OR6-5-2000, AMTI Inc., USA) were used. Before measuring, we installed eight cameras each to the right (non-dominant), left (dominant), and front of the participant, all of which were within a 7-m range. After preparing an environment in which the range of motion could be captured, we performed calibration to establish the spatial coordinates. The sampling rate of the camera was set to 120 frames/sec, and the margin of error was $0.3 \mathrm{~mm}$ or less. Next, we attached 19 reflective markers that were $15 \mathrm{~mm}$ in diameter on the lower limbs of the participants in accordance with the
Helen Hayes Markers Set, which allowed us to assess drop-landing movements.

Participants performed drop-landing movements from a vertical height of $30 \mathrm{~cm}$ (Kellis \& Kouvelioti, 2009). We measured these movements using a protocol described in a previous study to assess the mechanism of impact absorption by body segments. To ensure accuracy in the assessment, movements were assessed a total of three times for each participant. Researchers and participants determined whether their movements were successful. The data of ground reaction forces generated upon landing were collected at a sampling rate of $1,200 \mathrm{~Hz}$, synchronized by an analogue converter for measurement (A/D Converter, NI USB-6218, National Instruments, Hungary), and analyzed.

All kinematic and kinetic data were processed using Cortex 5 (Motion Analysis Corp., USA). The body was assumed to be a linked rigid body system. The center of mass of the pelvis and each segment were calculated by assigning coordinates to the central point of body joints and were used as parametric data. The two-dimensional (2D) data collected by the eight-image analysis camera were converted to three-dimensional (3D) data by the non-linear transformation method. To remove errors due to noises in data processing, Butterworth low-pass digital filtering was used for smoothing, and the cut-off frequency was set to $10 \mathrm{~Hz}$.

Analysis and process of data

Leg stiffness, PVF, changes in leg length (\%), loading rate, and dynamic postural stability index during a drop-landing movement were analyzed.

First, leg stiffness $\left(\mathrm{K}_{\text {leg }}\right)$ was calculated by a dimensionless quantification method (Silder et al., 2015) and was measured from the point of vertical force onset.

$$
\mathrm{K}_{\text {leg }}=\frac{\mathrm{PVF}}{\left(l_{o}-l_{\min }\right) / l_{o}^{\prime}}
$$

PVF was calculated by dividing the PVF produced upon landing $(\mathrm{N})$ by the participant's body weight. The 
resulting value was then calibrated $(\mathrm{N} / \mathrm{BW}) . l_{o}$ is the calibrated value of the rate of change in the leg length during the stance phase, and $l_{\min }$ is the minimum leg length. Leg length was measured from the center of pressure (Bullimore \& Burn, 2006) to the central point of the pelvis as shown in Figure 1, Figure 2.

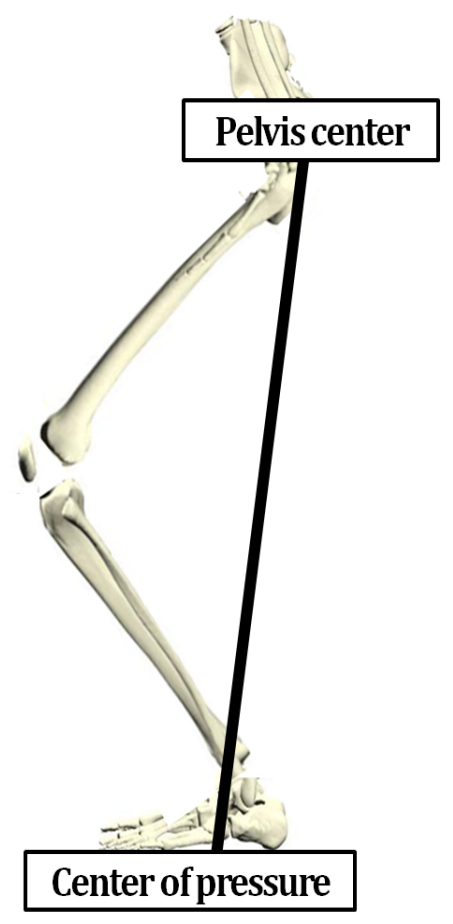

Figure 1. Leg length was estimated by calculating the distance from the center-of-pressure to the center of the pelvis

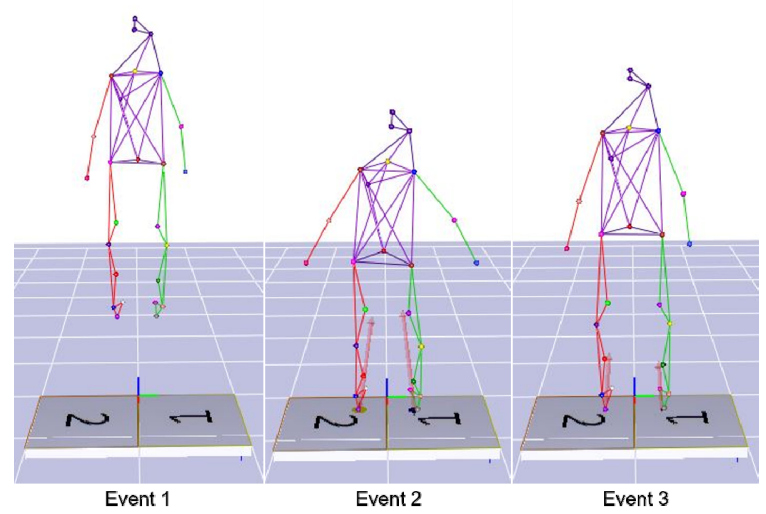

Figure 2. Analysis eventand phase
The loading rate was calculated based on (Munro, Miller, \& Fuglevand, 1987) data. It is the amount of force applied to the body per unit time upon landing. It did not include the $50 \mathrm{~N}$ that is lost during the process of determining the feet's position soon after performing a drop-land and contacting the ground (Cavanagh, 1990).

$$
\text { Loading rate }=\frac{\mathrm{PVF}=\mathrm{F} 50^{+}}{\Delta \mathrm{t}}
$$

DPSI was precisely calculated based on the three components of the ground reaction force (medial/lateral, anterior/posterior, and vertical) (Wikstrom et al., 2005). The termination point was set as the point at which PVF was generated, which allowed for an accurate calculation (Hyun \& Ryew, 2014), as shown in Formula 3.

$$
\begin{aligned}
& \text { MLSI }=\sqrt{\sum\left(0-\mathrm{F}_{\mathrm{xPVF}}\right)^{2} / \text { samples }} \\
& \text { APSI }=\sqrt{\sum\left(0-\mathrm{F}_{\mathrm{yPVF}}\right)^{2} / \text { samples }} \\
& \mathrm{VSI}=\sqrt{\sum\left(0-\mathrm{F}_{\mathrm{zPVF}}\right)^{2} / \text { samples }} \\
& \text { DPSI }=\text { MLSI }+\mathrm{APSI}+\mathrm{VSI}
\end{aligned}
$$

\section{Statistics}

Mean and standard deviations were found for leg stiffness, associated parameters, and DPSI using SPSS 21.0. Next, a two-way ANOVA was performed to analyze these parameters according to the landing foot (dominant and non-dominant leg) and type (FAI and MAI) of AI. Interaction on the main effect was interpreted through one way ANOVA. The level of statistical significance was set at $\mathrm{a}=.05$.

\section{Results}

Result of leg stiffness variables and loading rate

Measurements of the parameters of leg stiffness, and the rate of changes in the loading rate are shown in Table 1. Also, illustrates the relationship among dimensionless 
leg stiffness and each of the kinetic variable. No statistically significant differences in the PVF and loading rate were found according to the landing foot and the type of AI. Significant differences in the leg length were observed according to the landing foot and type of AI $(p<.01)$, without any interaction effects. Significant differences in the rate of changes in leg stiffness were found according to the landing foot and type of ankle stability $(p<.05)$, without any interaction effects.

Result of dynamic postural stability index

Changes in DPSI are shown in Table 2, and Figure 3. No significant differences in MSLI were found

Table 1. Result of leg stiffness variables according to ankle instability types during drop landing

\begin{tabular}{|c|c|c|c|c|c|c|c|}
\hline \multirow{2}{*}{ Section } & \multirow{2}{*}{ Landing leg } & \multicolumn{3}{|c|}{ Ankle instability types } & \multirow{2}{*}{ Source } & \multirow{2}{*}{$F$} & \multirow{2}{*}{ p-Value } \\
\hline & & FAI & MAI & Total average & & & \\
\hline \multirow{3}{*}{$\begin{array}{l}\text { Peak vertical force } \\
(\mathrm{N} / \mathrm{BW})\end{array}$} & Non-dominant leg & $1.70 \pm 0.36$ & $1.79 \pm 0.38$ & $1.74 \pm 0.36$ & A & .213 & .649 \\
\hline & Dominant leg & $1.99 \pm 0.51$ & $1.75 \pm 0.45$ & $1.87 \pm 0.48$ & $\mathrm{~L}$ & .607 & .444 \\
\hline & Total average & $1.85 \pm 0.45$ & $1.77 \pm 0.40$ & $1.81 \pm 0.42$ & $\mathrm{~A} \times \mathrm{L}$ & 1.048 & .316 \\
\hline \multirow{3}{*}{$\begin{array}{c}\text { Change in stance phase } \\
\text { leg length }(\%)\end{array}$} & Non-dominant leg & $91.07 \pm 1.86$ & $94.57 \pm 3.25$ & $92.82 \pm 2.44$ & A & 10.944 & $.003^{* *}$ \\
\hline & Dominant leg & $88.63 \pm 2.13$ & $94.57 \pm 1.51$ & $89.75 \pm 2.88$ & $\mathrm{~L}$ & 12.600 & $.002 * *$ \\
\hline & Total average & $89.85 \pm 2.30$ & $92.71 \pm 3.10$ & $91.28 \pm 3.05$ & $\mathrm{~A} \times \mathrm{L}$ & .542 & .469 \\
\hline \multirow{3}{*}{$\begin{array}{l}\text { Leg stiffness } \\
\text { (Dimensionless) }\end{array}$} & Non-dominant leg & $19.91 \pm 6.44$ & $35.78 \pm 13.75$ & $27.84 \pm 13.20$ & A & 6.781 & $.016^{*}$ \\
\hline & Dominant leg & $18.48 \pm 7.21$ & $21.56 \pm 9.36$ & $20.02 \pm 8.20$ & $\mathrm{~L}$ & 4.622 & $.042 *$ \\
\hline & Total average & $19.19 \pm 6.61$ & $28.67 \pm 13.50$ & $23.93 \pm 11.49$ & $\mathrm{~A} \times \mathrm{L}$ & 3.088 & .092 \\
\hline \multirow{3}{*}{$\begin{array}{l}\text { Loading rate } \\
\text { (N/BW/sec) }\end{array}$} & Non-dominant leg & $30.13 \pm 15.60$ & $47.84 \pm 24.75$ & $38.98 \pm 21.90$ & A & 1.511 & .231 \\
\hline & Dominant leg & $31.01 \pm 13.76$ & $28.98 \pm 9.76$ & $29.99 \pm 11.51$ & $\mathrm{~L}$ & 1.983 & .172 \\
\hline & Total average & $30.57 \pm 14.14$ & $38.41 \pm 20.55$ & $34.49 \pm 17.76$ & $\mathrm{~A} \times \mathrm{L}$ & 2.390 & .135 \\
\hline
\end{tabular}

Note: ${ }^{*} p<.05,{ }^{* *} p<.01$ : A, ankle instability of the main effect; $\mathrm{L}$, landing leg of the main effect, $\mathrm{A} \times \mathrm{L}$, interaction

Table 2. Dynamic postural stability index according to ankle instability types during drop landing

\begin{tabular}{|c|c|c|c|c|c|c|c|}
\hline \multirow{2}{*}{ Section } & \multirow{2}{*}{ Landing leg } & \multicolumn{3}{|c|}{ Ankle instability types } & \multirow{2}{*}{ Source } & \multirow{2}{*}{$F$} & \multirow{2}{*}{ p-Value } \\
\hline & & FAI & MAI & Total average & & & \\
\hline \multirow{3}{*}{$\begin{array}{l}\text { Medial-lateral } \\
\text { stability index }\end{array}$} & Non-dominant leg & $1.05 \pm 0.41$ & $0.99 \pm 0.42$ & $1.02 \pm 0.46$ & A & .532 & .473 \\
\hline & Dominant leg & $1.68 \pm 0.04$ & $1.39 \pm 0.41$ & $1.54 \pm 0.77$ & $\mathrm{~L}$ & 4.616 & $.042 *$ \\
\hline & Total average & $1.19 \pm 0.25$ & $1.19 \pm 0.45$ & $1.28 \pm 0.66$ & $\mathrm{~A} \times \mathrm{L}$ & .231 & .231 \\
\hline \multirow{3}{*}{$\begin{array}{l}\text { Anterior-posterior } \\
\text { stability index }\end{array}$} & Non-dominant leg & $1.31 \pm 0.62$ & $1.99 \pm 0.73$ & $1.65 \pm 0.74$ & A & 3.762 & .064 \\
\hline & Dominant leg & $1.28 \pm 0.49$ & $1.44 \pm 0.34$ & $1.36 \pm 0.42$ & $\mathrm{~L}$ & .187 & .187 \\
\hline & Total average & $1.30 \pm 0.54$ & $1.71 \pm 0.62$ & $1.51 \pm 0.61$ & $\mathrm{~A} \times \mathrm{L}$ & .243 & .246 \\
\hline \multirow{3}{*}{$\begin{array}{c}\text { Vertical stability } \\
\text { index }\end{array}$} & Non-dominant leg & $17.98 \pm 8.48$ & $24.59 \pm 9.83$ & $21.29 \pm 9.46$ & A & .772 & .388 \\
\hline & Dominant leg & $17.12 \pm 6.87$ & $15.64 \pm 4.66$ & $16.38 \pm 5.69$ & $\mathrm{~L}$ & 2.833 & .105 \\
\hline & Total average & $17.55 \pm 7.43$ & $20.11 \pm 8.73$ & $18.83 \pm 8.06$ & $\mathrm{~A} \times \mathrm{L}$ & 1.922 & .175 \\
\hline \multirow{3}{*}{$\begin{array}{l}\text { Dynamic postural } \\
\text { stability index }\end{array}$} & Non-dominant leg & $20.36 \pm 9.11$ & $27.57 \pm 10.47$ & $23.97 \pm 10.14$ & A & .788 & .383 \\
\hline & Dominant leg & $20.09 \pm 7.87$ & $18.48 \pm 4.94$ & $19.28 \pm 6.37$ & $\mathrm{~L}$ & 2.198 & .151 \\
\hline & Total average & $20.22 \pm 8.18$ & $23.03 \pm 9.17$ & $21.62 \pm 8.64$ & $\mathrm{~A} \times \mathrm{L}$ & 1.954 & .175 \\
\hline
\end{tabular}

Note: ${ }^{*} p<.05$ : A, ankle instability of the main effect; L, landing leg of the main effect, $\mathrm{A} \times \mathrm{L}$, interaction 

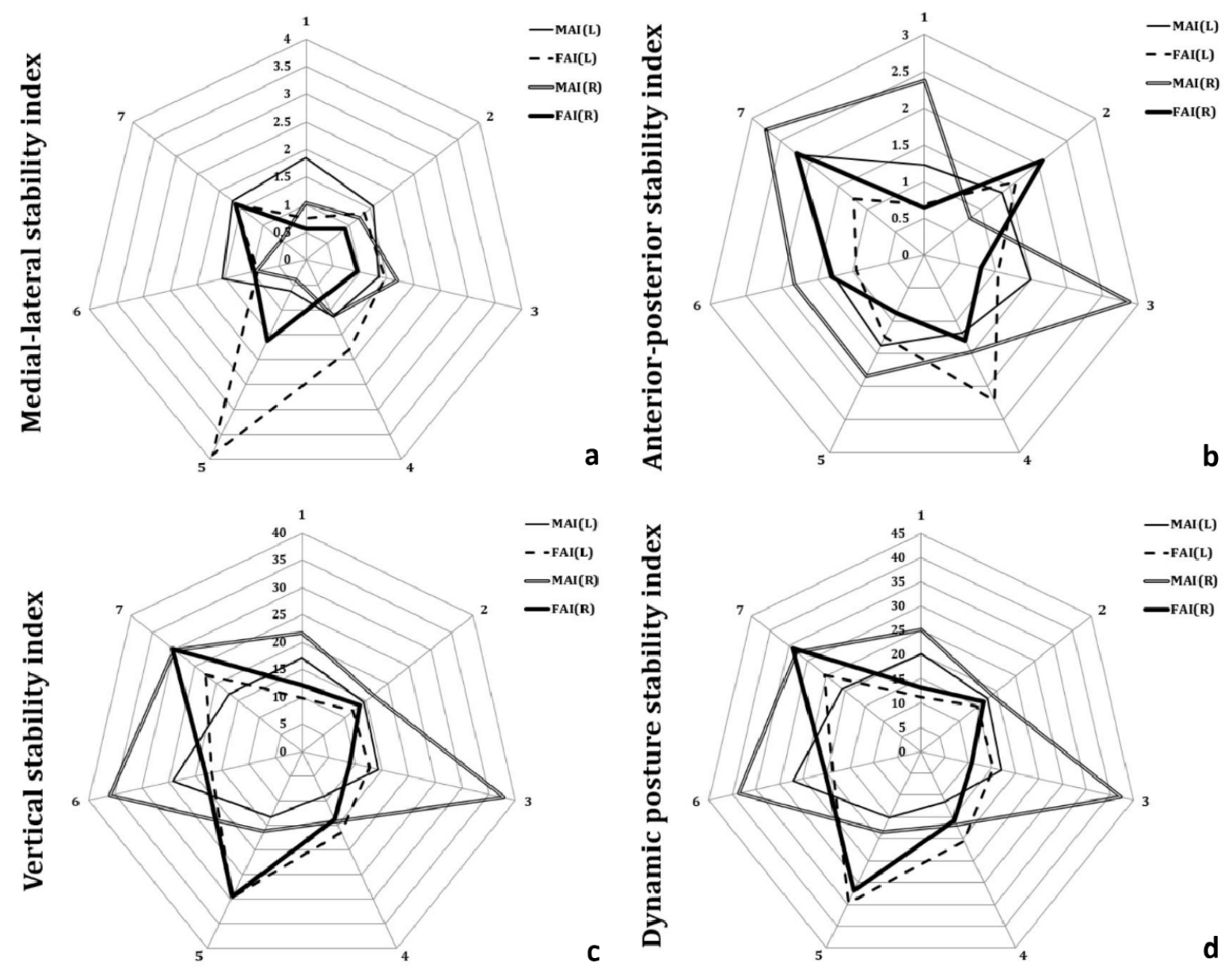

Figure 3. Results of medial-lateral (a), anterior-posterior (b), vertical (c), and dynamic postural stability index (d)

according to the type of AI. However, dominant ankle stability significantly decreased depending on the landing foot $(\mathrm{p}<.05)$. No significant differences in APSI, VSI, and DPSI were found according to the landing foot and type of AI.

\section{Discussion}

Athletes with AI are prone to sprains due to incorrect information regarding their position during landing after jumping (Konradsen, 2002), and tend to limit the movement of their ankles when landing (Eamonn Delahunt et al., 2006). While this movement restriction may be considered as a method to prevent ankle sprains (Cho, Kim, Lee, \& Lee, 2010), the body is a system of segments that are interconnected (Powers, 2010). Therefore, limiting the movement of one joint can lead to compensatory effects on other joints (Hertel, 2002; Yeung et al., 1994). Ankle sprains can eventually develop into CAI. An objective examination and assessment of the motor skills of athletes with CAI as well as resilience after rehabilitative therapy are important. However, existing studies associated with CAI resulted in inconsistent data (Brown, Padua, Marshall, \& Guskiewicz, 2008; Caulfield et al., 2004; Caulfield \& Garrett, 2002; Caulfield \& Garrett, 2004; Delahunt et al., 2006; Delahunt et al., 2007; Gribble et al., 2004). In the present study, athletes with CAI were divided into FAI and MAI groups according to 
lower limb movement restriction and leg stiffness. We then quantitatively analyzed postural instability in consideration of the risk for falls, which can result from AI.

In this study, lower limb stiffness and postural stability during drop landing were assessed. Leg stiffness is an appropriate parameter for assessing the impact force experienced by the body and lower limb stiffness. Leg stiffness is closely associated with vertical displacement of the center of the pelvis due to flexion/extension of the lower limb joints as well as with PVF (Hyun \& Ryew, 2016, 2017). Researchers in the field of biodynamics have paid close attention to the role of stiffness since the appropriate levels of stiffness are necessary for improving and maintaining motor function (Butler, Crowell, \& Davis, 2003; McMahon \& Cheng, 1990; Stefanyshyn \& Nigg, 1998), while levels of stiffness that are too high or low can lead to injuries (Butler et al., 2003). In this study, larger values of leg stiffness were found for the non-dominant leg, which was affected by ankle stability, than for the left leg, which was normal. This further depended on the landing foot. Increased stiffness was also observed for athletes with MAI relative to those with FAI. While no significant differences in PVF, which affects stiffness, were found according to the landing foot and the type of AI, the rate of change in the leg length was found to be an important factor associated with increased leg stiffness. In a study by (Brown et al., 2008), the MAI group had a smaller range of flexion/extension during drop-jump and step-down, and exhibited smaller plantar flexion of the ankle joints upon the initial contact with the ground. Minimizing these movements results in increased dependence on bones and decreased dependence on lateral ligaments, thereby ultimately reducing their risk for ankle sprains (Wright, Neptune, van den Bogert, \& Nigg, 2000). However, this can also significantly affect the rate of change in the lower limb length and further increase lower limb stiffness.

FAI results when nerve tissues within ligaments are damaged and torn, and it impairs proprioception and neuromuscular control (Freeman, 1965). Meanwhile, MAI occurs when ankle ligaments are physiologically relaxed, and results in less consistent motor patterns relative to FAI (Brown et al., 2009). When athletes with MAI perform the same exercise, those with MAI exhibit lower consistency in the range of motion of joints after a prolonged period relative to those with FAI (James, Dufek, \& Bates, 2000). Furthermore, MAI is associated with an increased risk for injuries. In addition, our findings showed that athletes with MAI had larger ranges of standard deviations for leg length (\%), leg stiffness, and loading rate than did those with FAI. This suggests that the consistency in the magnitude of leg stiffness may also be reduced when other tasks associated with jumping-landing are performed. On the other hand, while no significant changes in the loading rate were found according to the landing foot and the type of AI, athletes with MAI had the largest change of $47.84 \pm 24.75 \mathrm{~N} / \mathrm{BW} \cdot \mathrm{sec}-1$ for the non-dominant leg. Injuries and reduced motor function can result when a large force is repeatedly applied to the musculoskeletal system. Athletes with MAI absorb an impact force more poorly than do those with FAI (Hargrave, Carcia, Gansneder, \& Shultz, 2003). Accordingly, they may accumulate higher levels of stress in their lower limbs in a shorter period. Leg stiffness may be maintained at appropriate levels by maintaining normal lower limb function, and adapting to various ground conditions (Farley et al., 1998; Hyun \& Ryew, 2017; Silder et al., 2015). However, abnormal and asymmetrical landing postures may be observed on the side affected by AI due to an increased loading rate and failure to control leg stiffness.

In this study, data of ground reaction forces measured in three directions (medial/lateral, anterior/posterior, and vertical) during drop-landing movements were analyzed to assess DPSI (Wikstrom et al., 2005). No significant differences in APSI, VSI, and DPSI were found according to the landing foot and the type of AI. Patients who had ankle sprains in the past may use a hip strategy 
in the process of recovering a balance after perturbation (Beckman \& Buchanan, 1995). This strategy can initiate rapid hip muscle activation (Bullock-Saxton, Janda, \& Bullock, 1994). This may be because the use of hip joints increases as a compensatory mechanism to control unstable ankle movements.

However, MLSI of the dominant leg decreased according to the landing foot in our study, possibly due to the restricted movement of the non-dominant ankle joints affected by AI (Brown et al., 2008), and due to medial-lateral ground reaction force.

In summary, no significant changes in postural stability were found according to the type of AI (FAI and MAI) and the landing foot during drop-landing. However, leg movements were restricted in athletes with MAI relative to those with FAI as a compensatory mechanism to improve postural stability, indicating failed stiffness control. Further research using extrapolated center of mass and base of support to determine stable ranges of the body's center of mass based on kinematic and kinetic data to investigate the relationship between postural stability and leg stiffness is necessary.

This study sought to analyze leg stiffness and postural stability according to the type of AI, and the landing foot during drop landing. A motion analysis system was used to estimate the center of the pelvis and leg lengths, while two ground places were used to analyze kinematic parameters.

The rates of change in leg stiffness and leg length during drop-landing was significantly greater for MAI and the non-dominant leg. Meanwhile, MLSI was significantly increased in the dominant leg relative to the non-dominant leg. Therefore, people with mechanically unstable ankles may have higher risks associated with their musculoskeletal system due to a reduced ability to control lower limb stiffness. In addition, because they experience large changes in the loading rate, they may have difficulty relieving the landing force due to the physiologically relaxed state of their ankle ligaments.
While drop-landing was used in our research, more vigorous movements (e.g., stepping or jumping) are performed in sports activities and daily life (Brown et al., 2008). Drastic changes in the direction of movement accompanied by a decrease in speed may push the limits of neuromuscular control and musculoskeletal function. Furthermore, the extent of these effects varies depending on the movement patterns of the ankle (R. James et al., 2000). Therefore, to differentiate between the functional characteristics of FAI and MAI with greater clarity, various movements and environmental conditions must be considered in future studies.

\section{References}

Beckman, S. M., \& Buchanan, T. S. (1995). Ankle inversion injury and hypermobility: effect on hip and ankle muscle electromyography onset latency. Archives of Physical Medicine and Rehabilitation, 76, 1138-1143.

Blackburn, J. T., \& Padua, D. A. (2008). Influence of trunk flexion on hip and knee joint kinematics during a controlled drop landing. Clinical Biomechanics, 23, 313-319.

Brown, C., Padua, D., Marshall, S. W., \& Guskiewicz, K. (2008). Individuals with mechanical ankle instability exhibit different motion patterns than those with functional ankle instability and ankle sprain copers. Clinical Biomechanics, 23, 822-831.

Brown, C. N., Padua, D. A., Marshall, S. W., \& Guskiewicz, K. M. (2009). Variability of motion in individuals with mechanical or functional ankle instability during a stop jump maneuver. Clinical Biomechanics, 24, 762-768.

Bullimore, S. R., \& Burn, J. F. (2006). Consequences of forward translation of the point of force application for the mechanics of running. Journal of Theoretical Biology, 238, 211-219.

Bullock-Saxton, J., Janda, V., \& Bullock, M. (1994). The influence of ankle sprain injury on muscle activation during hip extension. International 
Journal of Sports Medicine, 15, 330-334.

Butler, R. J., Crowell, H. P., \& Davis, I. M. (2003). Lower extremity stiffness: implications for performance and injury. Clinical Biomechanics, 18, 511-517.

Caulfield, B., Crammond, T., O'Sullivan, A., Reynolds, S., \& Ward, T. (2004). Altered ankle-muscle activation during jump landing in participants with functional instability of the ankle joint. Journal of Sport Rehabilitation, 13, 189-200.

Caulfield, B., \& Garrett, M. (2002). Functional instability of the ankle: differences in patterns of ankle and knee movement prior to and post landing in a single leg jump. International Journal of Sports Medicine, 23(01), 64-68.

Caulfield, B., \& Garrett, M. (2004). Changes in ground reaction force during jump landing in subjects with functional instability of the ankle joint. Clinical Biomechanics, 19, 617-621.

Cavanagh, P. R. (1990). Biomechanics of Distance Running: ERIC.

Cho, J.-H., Kim, K.-H., Lee, H.-D., \& Lee, S.-C. (2010). Effects of Rehabilitation Duration on Lower Limb Joints Biomechanics dur ing Drop Landing in Athletes with Functional Ankle Instability. Korean Journal of Sport Biomechanics, 20, 395-406.

Delahunt, E., Monaghan, K., \& Caulfield, B. (2006). Altered neuromuscular control and ankle joint kinematics during walking in subjects with functional instability of the ankle joint. The American Journal of Sports Medicine, 34, 1970-1976.

Delahunt, E., Monaghan, K., \& Caulfield, B. (2007). Ankle function during hopping in subjects with functional instability of the ankle joint. Scandinavian Journal of Medicine \& Science in Sports, 17, 641-648.

Farley, C. T., Houdijk, H. H., Van Strien, C., \& Louie, M. (1998). Mechanism of leg stiffness adjustment for hopping on surfaces of different stiffnesses. Journal of Applied Physiology, 85, 1044-1055.
Freeman, M. (1965). Instability of the foot affer injuries to the lateral ligament of the ankle. Bone \& Joint Journal, 47, 669-677.

Gribble, P. A., Hertel, J., Denegar, C. R., \& Buckley, W. E. (2004). The effects of fatigue and chronic ankle instability on dynamic postural control. Journal of Athletic Training, 39, 321.

Hargrave, M. D., Carcia, C. R., Gansneder, B. M., \& Shultz, S. J. (2003). Subtalar pronation does not influence impact forces or rate of loading during a single-leg landing. Journal of Athletic Training, 38, 18.

Hertel, J. (2002). Functional anatomy, pathomechanics, and pathophysiology of lateral ankle instability. Journal of Athletic Training, 37, 364.

Hyun, S. H., \& Ryew, C. C. (2014). Investigation of the Ground Reaction Force Parameters According to the Shoes heel Heights and Landing Distance during Downward Stairs on Bus. Korean Journal of Sport Biomechanics, 24, 151-160.

Hyun, S. H., \& Ryew, C. C. (2016). Relationship between Dimensionless Leg Stiffness and Kinetic Variables during Gait Performance, and its Modulation with Body Weight. Korean Journal of Sport Biomechanics, 26, 249-255.

Hyun, S. H., \& Ryew, C. C. (2017). Relationship between Leg Stiffness and Kinematic Variables According to the Load while Running. Korean Journal of Sport Biomechanics, 27, 109-116.

James, C. (2004). Considerations of movement variability in biomechanics research. Innovative Analyses of Human Movement, 29-62.

James, C. R., Dufek, J. S., \& Bates, B. T. (2000). Effects of injury proneness and task difficulty on joint kinetic variability. Medicine and Science in Sports and Exercise, 32, 1833-1844.

Johnston 3rd, R., Howard, M. E., Cawley, P. W., \& Losse, G. M. (1998). Effect of lower extremity muscular fatigue on motor control performance. Medicine and Science in Sports and Exercise, 30, 1703-1707. 
Hiller, C. E., Kilbreath, S. L., \& Refshauge, K. M. (2011). Chronic ankle instability: evolution of the model. Journal of athletic training, 46(2), 133-141.

Hiller, C. E., Refshauge, K. M., Bundy, A. C., Herbert, R. D., \& Kilbreath, S. L. (2006). The Cumberland ankle instability tool: a report of validity and reliability testing. Archives of physical medicine and rehabilitation, 87(9), 1235-1241.

Kellis, E., \& Kouvelioti, V. (2009). Agonist versus antagonist muscle fatigue effects on thigh muscle activity and vertical ground reaction during drop landing. Journal of Electromyography and Kinesiology, 19(1), 55-64.

Wright, C. J., Arnold, B. L., Ross, S. E., Ketchum, J., Ericksen, J., \& Pidcoe, P. (2013). Clinical examination results in individuals with functional ankle instability and ankle-sprain copers. Journal of athletic training, 48(5), 581-589.

Konradsen, L. (2002). Sensori-motor control of the uninjured and injured human ankle. Journal of Electromyography and Kinesiology, 12, 199-203.

McMahon, T. A., \& Cheng, G. C. (1990). The mechanics of running: how does stiffness couple with speed? Journal of biomechanics, 23, 65-78.

McNitt-Gray, J. L. (1991). Kinematics and impulse characteristics of drop landings from three heights. International Journal of Sport Biomechanics, 7,
201-224.

Munro, C. F., Miller, D. I., \& Fuglevand, A. J. (1987). Ground reaction forces in running: a reexamination. Journal of Biomechanics, 20, 147-155.

Powers, C. M. (2010). The influence of abnormal hip mechanics on knee injury: a biomechanical perspective. Journal of Orthopaedic \& Sports Physical Therapy, 40, 42-51.

Silder, A., Besier, T., \& Delp, S. L. (2015). Running with a load increases leg stiffness. Journal of Biomechanics, 48, 1003-1008.

Stefanyshyn, D. J., \& Nigg, B. M. (1998). Dynamic angular stiffness of the ankle joint during running and sprinting. Journal of Applied Biomechanics, 14, 292-299.

Wikstrom, E. A., Tillman, M. D., Smith, A. N., \& Borsa, P. A. (2005). A new force-plate technology measure of dynamic postural stability: the dynamic postural stability index. Journal of Athletic Training, 40, 305 .

Wright, I., Neptune, R., van den Bogert, A. J., \& Nigg, B. (2000). The influence of foot positioning on ankle sprains. Journal of Biomechanics, 33, 513-519.

Yeung, M., Chan, K.-M., So, C., \& Yuan, W. (1994). An epidemiological survey on ankle sprain. British Journal of Sports Medicine, 28, 112-116. 